\title{
Impact of Lockdown due to Covid-19 on the Lifestyle Changes of Employees in India: A Cross-sectional Analysis of Personnel Who Work at Office Versus Work from Home
}

\author{
Arumugam Elangovan ${ }^{1 *}$, Alex Eapen ${ }^{2}$, V. M. Padmapriya ${ }^{3}$, Jaganathasamy Nagaraj ${ }^{3}$, \\ Radhakrishnan Kannan ${ }^{3}$, Muthusamy Ravi ${ }^{3}$, Aridoss Santhakumar ${ }^{3}$, Mathiyazhakan \\ Malathi $^{3}$, Govindhasamy Elavarasu ${ }^{3}$ and Divya A. Merciline ${ }^{4}$ \\ 'Department of Computing and Information Science, ICMR - National Institute of Epidemiology \\ Chennai - 600077, Tamil Nadu, India; elangovan@nie.gov.in \\ ${ }^{2}$ ICMR - National Institute of Malaria Research (Field Unit), ICMR-NIE campus, \\ Chennai -600077, Tamil Nadu, India; alexeapen@yahoo.com \\ ${ }^{3}$ ICMR-National Institute of Epidemiology, Chennai - 600077, Tamil Nadu, India; \\ padmanie2019@gmail.com,nagarajicmr@gmail.com, \\ kanstar000@gmail.com, ravi@nie.gov.in, santhakumar.aridoss@gmail.com, \\ mithmals@gmail.com, elavarasug@gmail.com, \\ ${ }^{4}$ Department of Clinical Psychology, Sri Ramachandra Institute of higher \\ Education and Research, Chennai, Tamil Nadu, India; divyaclipsian@gmail.com
}

\begin{abstract}
The nationwide lockdown implemented due to COVID-19 drastically affected the working pattern of people. Only limited staff were allowed to Work At Office (WAO) while the rest were asked to Work From Home (WFH). Employees of both the categories faced challenges due to restricted movements and safety policies. The study was planned to assess and compare the lifestyle changes of WAO and WFH employees during the lockdown. An online cross-sectional study was designed which included employees of both Government and private sectors. Electronic Data Capture method was used to collect the data after obtaining their online consent and/assent forms by circulating a web-page developed using Research Electronic Data Capture software system. Multinomial logistic regression analysis revealed that the employees of WFH were at a higher risk than WAO with respect to their food intake and eating patterns. Our analysis indicated that the risk of weight gain was higher (OR: 1.51, $P<0.005)$ in WFH group besides, a significant $(P<0.005)$ increase in time spent on mobile by the WFH. An increase in the intake of fruits and vegetables was observed in both the groups. The study highlights the need for awareness on timely eating habits and minimal use of gadgets while working from home. Encouraging periodic rotation of the staff will facilitate a balanced lifestyle among working personnel. Fitness programmes may be made for the WFH staffs, especially to the younger employees to avoid the risk of obesity.
\end{abstract}

Keywords: Covid-19, Lifestyle Changes, Lockdown, Work from Home, Work at Office

${ }^{*}$ Author for correspondence 


\section{Introduction}

The lockdown implemented due to the COVID-19 pandemic made a drastic change among the people globally. In India, the public, irrespective of the state they resided, faced challenges and critical situations throughout the turmoil period. Restricted movement and safety policies greatly affected the mundane activities of the people while social and entertainment activities ceased to exist. This caused an impact on the dietary pattern, sleeping habits, daily working hours, and physical activities of people ${ }^{1}$. Announcement of lockdown induced panic-buying and stocking of essential goods such as groceries and medicines ${ }^{2}$. Although the lockdown was extended in phases, the initial phase of lockdown from 24 March 2020 to 31 May 2020 was strikingly challenging, with highly restricted public movement, except for essential and emergency services. The lockdown and safety protocols made a substantial impact on the employees of both public and private sectors in terms of commuting, office hours, working pattern and lifestyle. Only a fraction of the workforce was allowed to WAO on a rotation-basis in most of the government and private offices/industries, with strict adherence to safety guidelines such as maintenance of social distancing, mask-wearing and routine temperature checks ${ }^{3}$. Most employees such as those residing at distant places, pregnant women, those who are above 55 years of age and with underlying co-morbidities were asked to Work from Home (WFH). ${ }^{4}$

Surprisingly both these categories of employees faced certain challenges based on their working environment. For WFH employees, their home environment might be challenging than their usual office-space. Whereas for WAO employees adhering to the safety protocols and commuting would have been more challenging. Fear of job-security, continuous telecast of COVID-19 related news/messages induced frustration and depression leading to negative thoughts ${ }^{5}$. However, given the advantages of digital technologies, taking a break from the routine activities, and spending more time with family, while efficiently managing their office work, was also appreciated by people. Nonetheless, the lockdown was expected to have a great impact on the dietary and sleeping patterns as well as the infotainment of the employees. Considering all the related changes that could have been occurred during the lockdown period, in this study we planned to assess the lifestyle changes of the employees, those who work at office and those who work from home.

\section{Materials and Methods}

Since there was absolutely no means of conducting a face-to-face interview due to the pandemic situation, an Electronic Data Capture (EDC) method was developed to collect the data after obtaining their online consent forms along with their hand-signature by creating a webpage using Research Electronic Data Capture (Redcap) ${ }^{6}$. The web-page was circulated through WhatsApp as the same was considered easy to be used by anyone who keeps a smart-phone. The online tool was pre-tested and validated appropriately. This study was conducted between 24 June and 3 July 2020 during the fifth phase of the partial lockdown.

The online questionnaire consisted of the questions relating to routine activities and the most common factors affecting their lifestyle. These include dietary habits, sleeping pattern, use of electronic devices, and physical activities. The questions were framed such that the respondents recorded changes in their lifestyle before and during the lockdown. For example, to know the changes in sleeping pattern, the question framed was: "What is your average bedtime (night) during this lockdown period as compared to before lockdown? (Options: No changes, 1 hour later, 2 hours later, 3 hours later and above). The survey data was transferred and stored in real-time, at the central server.

\section{Study Design}

It is a cross-sectional study aimed to target employees of both the Government and private sectors. A web link of the survey questionnaire along with the participant information sheet and consent form was circulated to various private and government institutions in India through WhatsApp.

\section{Study Population}

No pre-calculated sample size was fixed, as it was planned to collect data from as many employees as possible from both the groups. The respondents were categorized into 2 groups, Group-1 was employees WAO and Group-2 was those WFH. 


\section{Data Management and Analysis}

The proportions were calculated to describe the categorical variables. Pearson's chi-square test was used to test the differences in lifestyle changes between WAO and WFH. The strength of the relationship between two variables was checked by Cramer's $(V)$ test $^{7}$. The variables significant at the chi-square test $(P<0.05)$ were selected for multinomial logistic regression to investigate the association between the dependent variable (working status) and independent variables (lifestyle variables). The model fitness was assessed by Likelihood Ratio (LR) test. All the analysis was performed using STATA version 15.0.

\section{Ethical Considerations}

The study was approved by both the Institutional Ethics Committees (Ref. No: NIE/IHEC/202005-01 dt. 23 June 2020 and PHB/NIMR/EC/2020/152 dt. 25 June 2020) of ICMR-National Institute of Epidemiology, Chennai and ICMR-National Institute of Malaria Research, New Delhi respectively. The survey was done after obtaining proper online informed-consent from all the respondents. Participants were informed about their willingness to participate voluntarily and were also given clear information regarding the risks and benefits of their participation.

Table 1. Socio-demographic factors of the participants

\begin{tabular}{|c|c|c|c|c|c|c|c|}
\hline & \multicolumn{6}{|c|}{ Working status } \\
\hline & & \multicolumn{2}{|c|}{ Work at Office } & \multicolumn{2}{|c|}{ Work from Home } & \multicolumn{2}{|c|}{ Total } \\
\hline & & $\mathrm{N}$ & $\%$ & $\mathrm{~N}$ & $\%$ & $\mathrm{~N}$ & $\%$ \\
\hline \multirow{3}{*}{ Gender } & Male & 352 & $55.0 \%$ & 187 & $48.8 \%$ & 539 & $52.7 \%$ \\
\hline & Female & 287 & $44.8 \%$ & 196 & $51.2 \%$ & 483 & $47.2 \%$ \\
\hline & Transgender/Hijra & 1 & $0.2 \%$ & 0 & $0.0 \%$ & 1 & $0.1 \%$ \\
\hline \multirow{4}{*}{ Age Group } & $<=25$ Yrs. & 66 & $10.3 \%$ & 58 & $15.1 \%$ & 124 & $12.1 \%$ \\
\hline & 26-39 Yrs. & 340 & $53.1 \%$ & 177 & $46.2 \%$ & 517 & $50.5 \%$ \\
\hline & 40-59 Yrs. & 224 & $35.0 \%$ & 142 & $37.1 \%$ & 366 & $35.8 \%$ \\
\hline & $>=60$ Yrs. & 10 & $1.6 \%$ & 6 & $1.6 \%$ & 16 & $1.6 \%$ \\
\hline \multirow{4}{*}{ Education } & $11-12$ th & 46 & $7.2 \%$ & 16 & $4.2 \%$ & 62 & $6.1 \%$ \\
\hline & 6-10th & 4 & $0.6 \%$ & 0 & $0.0 \%$ & 4 & $0.4 \%$ \\
\hline & Graduate & 147 & $23.0 \%$ & 126 & $32.9 \%$ & 273 & $26.7 \%$ \\
\hline & Post Graduate & 443 & $69.2 \%$ & 241 & $62.9 \%$ & 684 & $66.9 \%$ \\
\hline
\end{tabular}


Table 2. Distribution of lifestyle characteristics of the participants between Work From Home and Work At Office

\begin{tabular}{|c|c|c|c|c|c|}
\hline \multirow{3}{*}{ Variables } & Work From Home & Work At Office & Total & \multirow{3}{*}{$P$ value } & \multirow{3}{*}{ Effect Size } \\
\hline & $n=383$ & $\mathrm{n}=640$ & $\mathrm{~N}=1023$ & & \\
\hline & $(\%)$ & $(\%)$ & $(\%)$ & & \\
\hline \multicolumn{6}{|l|}{ Sleeping habits } \\
\hline \multicolumn{6}{|l|}{ Wakeup time } \\
\hline Early (before routine time) & 8.4 & 9.7 & 9.2 & \multirow{5}{*}{$<0.001^{\star *}$} & \multirow{5}{*}{0.278} \\
\hline 1 hour later & 28.2 & 20.2 & 23.2 & & \\
\hline 2 hours later & 24 & 9.8 & 15.1 & & \\
\hline 3 hours \& above & 6.8 & 2.7 & 4.2 & & \\
\hline No changes & 32.6 & 57.2 & 48.0 & & \\
\hline \multicolumn{6}{|l|}{ Night bed time } \\
\hline Early & 6 & 6.3 & 6.2 & & \\
\hline 1 hour later & 18.5 & 22 & 20.7 & \multirow{4}{*}{$<0.001^{\star *}$} & \multirow{4}{*}{0.19} \\
\hline 2 hours later & 24.3 & 15.2 & 18.6 & & \\
\hline 3 hours \& above & 19.3 & 10.6 & 13.9 & & \\
\hline No changes & 31.6 & 45.6 & 40.4 & & \\
\hline \multicolumn{6}{|l|}{ Food intake habits } \\
\hline \multicolumn{6}{|l|}{ Breakfast } \\
\hline Early & 4.4 & 5 & 4.8 & \multirow{6}{*}{$<0.001^{\star \star}$} & \multirow{6}{*}{0.298} \\
\hline 1 hour later & 33.2 & 18.9 & 24.3 & & \\
\hline 2 hours later & 20.1 & 8.8 & 13.0 & & \\
\hline 3 hours \& above & 4.7 & 3.1 & 3.7 & & \\
\hline Skipped & 8.1 & 5.5 & 6.5 & & \\
\hline No changes & 29.5 & 58.8 & 47.8 & & \\
\hline \multicolumn{6}{|l|}{ Lunch } \\
\hline Early & 2.6 & 4.7 & 3.9 & & \\
\hline 1 hour later & 31.1 & 20 & 24.2 & \multirow{4}{*}{$<0.001^{\star *}$} & \multirow{4}{*}{0.254} \\
\hline 2 hours later & 21.9 & 10.9 & 15.0 & & \\
\hline 3 hours \& above & 6.5 & 3 & 4.3 & & \\
\hline Skipped & 2.1 & 4.2 & 3.4 & & \\
\hline No changes & 35.8 & 56.7 & 48.9 & & \\
\hline \multicolumn{6}{|l|}{ Dinner } \\
\hline Early & 7 & 6.3 & 6.6 & & \\
\hline 1 hour later & 21.4 & 16.1 & 18.1 & \multirow{4}{*}{$0.007^{\star}$} & \multirow{4}{*}{0.125} \\
\hline 2 hours later & 11.7 & 7.2 & 8.9 & & \\
\hline 3 hours \& above & 3.1 & 3 & 3.0 & & \\
\hline Skipped & 2.3 & 1.4 & 1.7 & & \\
\hline No changes & 54 & 65.6 & 61.3 & & \\
\hline \multicolumn{6}{|l|}{ Food Intake } \\
\hline Decreased & 20.6 & 21.1 & 20.9 & & \\
\hline Increased & 39.7 & 31.6 & 34.6 & $0.019^{*}$ & 0.088 \\
\hline No changes & 38.9 & 46.7 & 43.8 & & \\
\hline
\end{tabular}




\begin{tabular}{|c|c|c|c|c|c|}
\hline Vegetable Intake & & & & & \\
\hline Decreased & 9.4 & 11.6 & 10.8 & \multirow{3}{*}{0.211} & \multirow{3}{*}{0.055} \\
\hline Increased & 54.3 & 48.9 & 50.9 & & \\
\hline No changes & 36.3 & 39.5 & 38.3 & & \\
\hline \multicolumn{6}{|l|}{ Fruit Intake } \\
\hline Decreased & 19.1 & 18.2 & 18.6 & \multirow{3}{*}{0.176} & \multirow{3}{*}{0.058} \\
\hline Increased & 46.1 & 41.2 & 43.0 & & \\
\hline No changes & 34.8 & 40.6 & 38.4 & & \\
\hline \multicolumn{6}{|l|}{ Sea Food/Meat } \\
\hline Decreased & 33.2 & 33.1 & 33.2 & \multirow{5}{*}{0.07} & \multirow{5}{*}{0.110} \\
\hline Increased & 14.1 & 11.7 & 12.6 & & \\
\hline No changes & 20.9 & 21.8 & 21.5 & & \\
\hline Stopped time being & 7.1 & 9.8 & 8.8 & & \\
\hline Unavailable & 3.4 & 7.3 & 5.8 & & \\
\hline \multicolumn{6}{|l|}{ Out Door food } \\
\hline Decreased & 30.4 & 29.9 & 30.1 & \multirow{5}{*}{0.304} & \multirow{5}{*}{0.101} \\
\hline Do not take outdoor foods & 29.1 & 27.2 & 27.9 & & \\
\hline Increased & 2.9 & 3.8 & 3.4 & & \\
\hline No changes & 5.5 & 11.0 & 9.0 & & \\
\hline Temporarily Stopped & 32.2 & 28.0 & 29.6 & & \\
\hline \multicolumn{6}{|l|}{ Snacks/Junk food Intake } \\
\hline Decreased & 38.7 & 40.1 & 39.6 & \multirow{3}{*}{0.16} & \multirow{3}{*}{0.071} \\
\hline Increased & 23.8 & 18.1 & 20.2 & & \\
\hline No changes & 20.4 & 23.1 & 22.1 & & \\
\hline No habit of Snacking & 17.0 & 18.7 & 18.1 & & \\
\hline \multicolumn{6}{|l|}{ Physical Activities } \\
\hline \multicolumn{6}{|l|}{ Perception on Weight } \\
\hline Gained & 38.9 & 29.1 & 32.8 & \multirow{3}{*}{$0.006^{*}$} & \multirow{3}{*}{0.101} \\
\hline Loss & 15.7 & 19.2 & 17.9 & & \\
\hline No changes & 45.2 & 50.9 & 48.8 & & \\
\hline \multicolumn{6}{|l|}{ Exercise (per week) } \\
\hline Within 3 Hours & 41.2 & 36.2 & 38.1 & & \\
\hline 3-7 Hours & 10.5 & 9.7 & 10.0 & \multirow{3}{*}{0.191} & \multirow{3}{*}{0.068} \\
\hline$>7$ Hours & 5.5 & 4.4 & 4.8 & & \\
\hline Did not do any activity & 42.8 & 49.7 & 47.1 & & \\
\hline \multicolumn{6}{|l|}{ Time spent/Social media usage } \\
\hline \multicolumn{6}{|l|}{ Mobile usage } \\
\hline Within 2 hours & 31.1 & 30.2 & 30.5 & & \\
\hline 2- 4 hours & 24 & 20 & 21.5 & \multirow{4}{*}{$<0.001^{\star *}$} & \multirow{4}{*}{0.147} \\
\hline 4- 5 hours & 8.6 & 6.3 & 7.2 & & \\
\hline 5 hours and above & 17.5 & 12.2 & 14.2 & & \\
\hline No changes & 18 & 30 & 25.5 & & \\
\hline
\end{tabular}




\begin{tabular}{|c|c|c|c|c|c|}
\hline Watching TV & & & & & \\
\hline Within 2 hours & 29.5 & 30 & 29.8 & \multirow{5}{*}{0.093} & \multirow{5}{*}{0.094} \\
\hline 2- 4 hours & 11.2 & 10.2 & 10.6 & & \\
\hline 4- 5 hours & 3.4 & 1.7 & 2.3 & & \\
\hline 5 hours and above & 1.0 & 3.1 & 2.3 & & \\
\hline No changes & 44.6 & 40.5 & 42.0 & & \\
\hline
\end{tabular}

\section{Dietary Habits and Weight-gain}

A significant difference in eating-time and food intake was observed between the groups as shown in Table 2 . Breakfast time was delayed up to 2 hours among WFH group, with a significantly higher proportion of WFH tending to skip breakfast ( $8.1 \%$ vs $5.5 \%)$. Our analysis indicated an association between late wake-up time and delay in eating-time $(\mathrm{r}=0.40, p<0.05)$. An increased intake of snacks/junk-food was observed among $23.8 \%$ of the WFH group whereas it was decreased among $40.1 \%$ of the WAO group. About $18 \%$ of the people did not have the habit of snacking.

Vegetable and fruit intake have increased in a considerable proportion in both the groups by $50.9 \%$ and $43.0 \%$ respectively. Consumption of outdoor food was decreased among $30.1 \%$ of the employees whereas it was temporarily stopped by $29.6 \%$. Likewise, the intake of dairy products was considerably increased and that of meat and seafood was reduced among 33\% employees of the both groups. Overall increase in food intake was higher in WFH group (39.7\%) as compared with WAO (31.6\%). About $20.9 \%$ of the people decreased their food intake as compared to pre-lockdown time. A considerable increase in body weight was observed in both groups, and however it was higher among the WFH group (Figure 1). Our analysis revealed that there was a positive correlation with their increased food intake and weight gain $(r=0.36$, $p<0.05)$.

\section{Physical activities}

About $52.9 \%$ in both the groups were involved in physical activities like walking, jogging and running, whereas the remaining (47.1\%) did not do any such of physical activities during the lockdown. A majority (38.1\%) from both the group were engaged in physical activities only up to 3 hours per week followed by $10 \%$ between 3-7 hours per week.

\section{Electronic Device Utilization}

A significant difference in mobile usage $(P<0.001$, $V=0.147$ ) was seen between the two groups. The extra hours spent on mobile was observed to be high in both the groups and nearly three-fourth spent more time on gadgets compared to pre-lockdown. Further, it was perceived that nearly $14.2 \%$ of the total participants spent their time on mobile for more than 5 hours, indicating that one-fifth of a day was spent with mobile devices. In total, nearly half of the people spent their extra time on watching TV and no significant difference was observed between the WFH and WAO groups. Overall, nearly $50 \%$ of the people were watching news on TV followed by movies (20\%).

\section{Analysis by Multinomial Logistic Regression}

The multinomial logistic regression analysis revealed that the WFH group had significantly more chances of altered sleeping and eating routines than WAO group. The odds of delaying breakfast among WFH group by one hour was 3.49 times, by two hours was 4.56 times and by three hours was 2.99 times higher than WAO group. The odds of skipping breakfast among WFH group was 2.95 times higher. Likewise, the odds of delaying lunch and dinner was higher in the WFH as presented in (Table 3 ). Concurrently, the odds of delayed bedtime and delayed wakeup routine was higher among the WFH group than the WAO group (Table 3).

Our analysis showed that the odds of weight gain was higher (OR: $1.51, P<0.005)$ in the WFH group as compared to WAO, as expected (Table 3, Figure 1). In particular, the chances of weight gain were higher among young employees in the WFH group and older employees of the WAO group (Figure 2). We also observed a significant $(\mathrm{P}<0.005)$ increase in time spent on mobile by the WFH category when compared to WAO. 
Table 3. Lifestyle characteristics of WFH compared to WAO by Multinomial logistic regression

\begin{tabular}{|c|c|}
\hline Variables & $\mathrm{OR}^{\wedge}(95 \% \mathrm{CI})$ \\
\hline \multicolumn{2}{|l|}{ Breakfast } \\
\hline Early & $1.76(0.95-3.30)$ \\
\hline 1 hour later & $3.49(2.52-4.84)^{* * *}$ \\
\hline 2 hours later & $4.56(3.06-6.85)^{* * *}$ \\
\hline 3 hours and above & $2.99(1.53-5.86)^{\star \star}$ \\
\hline Skipped & $2.95(1.74-5.00)^{\star * *}$ \\
\hline \multicolumn{2}{|l|}{ Lunch } \\
\hline Early & $0.88(0.42-1.86)$ \\
\hline 1 hour later & $2.46(1.79-3.38)^{\star * *}$ \\
\hline 2 hours later & $3.18(2.19-4.62)^{\star * *}$ \\
\hline 3 hours and above & $3.49(1.86-6.53)^{\star * *}$ \\
\hline Skipped & $0.79(0.38-1.77)$ \\
\hline \multicolumn{2}{|l|}{ Dinner } \\
\hline Early & $1.37(0.82-2.29)$ \\
\hline 1 hour later & $1.62(1.16-2.26)^{\star}$ \\
\hline 2 hours later & $1.99(1.27-3.09)^{\star *}$ \\
\hline 3 hours and above & $1.28(0.61-2.69)$ \\
\hline Skipped & $2.02(0.79-5.19)$ \\
\hline \multicolumn{2}{|l|}{ Food intake } \\
\hline Decreased & $1.17(0.84-1.65)$ \\
\hline Increased & $1.51(1.13-2.01)^{*}$ \\
\hline \multicolumn{2}{|l|}{ Wakeup time } \\
\hline Early & $1.51(0.94-2.42)$ \\
\hline 1 hour later & $2.45(1.77-3.40)^{\star * *}$ \\
\hline 2 hours later & $4.27(2.93-6.23)^{\star * \star}$ \\
\hline 3 hours and above & $4.48(2.35-8.53)^{* * *}$ \\
\hline \multicolumn{2}{|l|}{ Bedtime (Night) } \\
\hline Early & $1.38(0.80-2.42)$ \\
\hline 1 hour later & $1.21(0.85-1.73)$ \\
\hline 2 hours later & $2.31(1.62-3.30)^{* * *}$ \\
\hline 3 hours and above & $2.62(1.78-3.89)^{* * *}$ \\
\hline \multicolumn{2}{|l|}{ Weight } \\
\hline Gain & $1.51(1.14-2.01)^{\star *}$ \\
\hline Loss & $0.92(0.64-1.32)$ \\
\hline \multicolumn{2}{|l|}{ Mobile usage } \\
\hline Within 2 hours & $1.72(1.20-2.45)^{\star *}$ \\
\hline 2- 4 hours & $2.00(1.36-2.94)^{* * *}$ \\
\hline 4- 5 hours & $2.30(1.34-3.93)^{* *}$ \\
\hline 5 hours and above & $2.39(1.56-3.66)^{* * *}$ \\
\hline \multicolumn{2}{|c|}{ 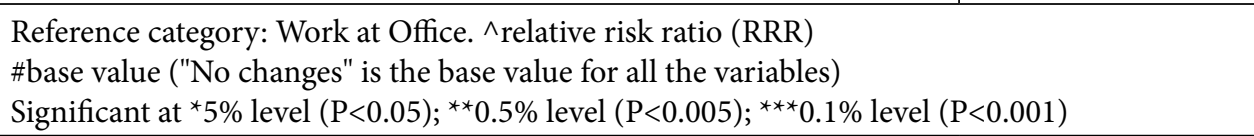 } \\
\hline
\end{tabular}




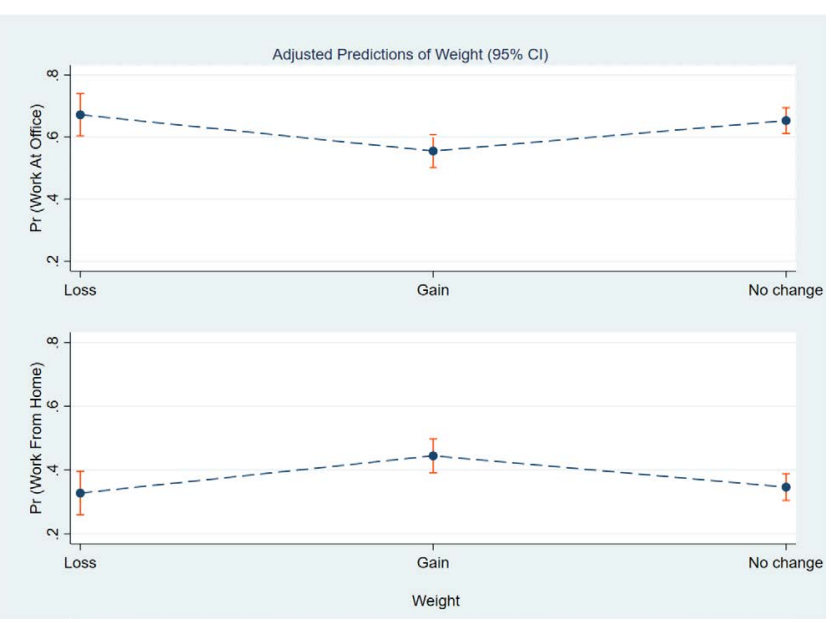

Figure 1. Comparison of weight gain between Work from Home and Work At office groups.

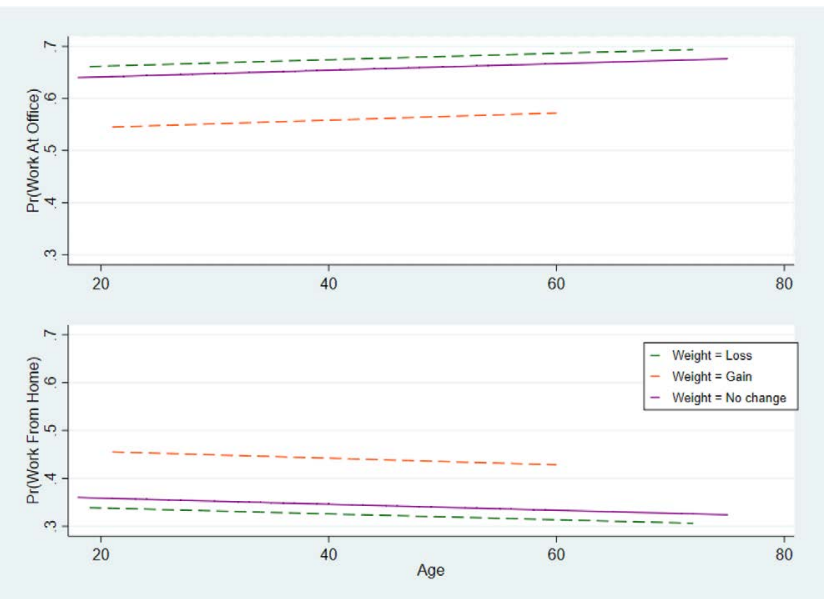

Figure 2. Weight gain among younger employees of the participants.

\section{Discussion}

Our study suggests that staying at home during the lockdown has resulted in altered sleeping and eating patterns, dietary modifications, increased gadget-usage and decreased or lack of physical activity. Sleep is much essential for a healthy lifestyle; as disturbed circadian rhythm may lead to emotional distress ${ }^{8}$. During lockdown due to prolonged sleeping hours in the morning, delayed wakeup time was observed in an Indian study ${ }^{9}$ A study conducted among Chinese population revealed that home-based workers were more likely to increase their sleep duration and skipped their breakfast which is consistent with our study ${ }^{10}$. In the present study, a higher proportion of WFH employees reported delayed wakeup and bedtime routine than WAO group during the lockdown. This may cause psychological distress, with irregular, disrupted sleeping habits due to reduced daylight exposure ${ }^{11,12}$. Our analysis revealed that waking up late in the morning hours has a positive association with skipping breakfast. Skipping meals tends to alter the metabolic state of a person ${ }^{7}$ and its consequences could be seen as influencing body weight gain (obesity), high glucose, fasting insulin level and high cholesterol levels ${ }^{13,14}$.

Dietary changes were observed in both groups; the total food intake and consumption of fruits and vegetables was increased predominantly, whereas the consumption of meat, seafood, snacks and outside food had reduced or temporarily stopped among a major proportion of the respondents. Fear of infection through meat/seafood ${ }^{15}$, unavailability or disruption in the supply chain of certain foods might be some factors contributing to the decreased intake ${ }^{16}$.

The higher intake of food was associated with weight gain in studies conducted in Poland and Italy ${ }^{17-}$ ${ }^{19}$. Further, an Italian study among obese individuals reported increased intake of fruits, snacks and meat during the lockdown ${ }^{20}$. In another study done among Spain population, only $19 \%$ of participants reported that snacking substantially increased during the home lockdown ${ }^{21}$. The habits of frequent eat outs and snacks between meals were not healthy during confinement period as reported by an international online survey done by 35 research organizations $s^{22}$. A study conducted in Spain also reported that lockdown influenced poor dietary habits ${ }^{23}$. Increased consumptions of vegetables and fruits, and decreased snacking as reported in our study suggests that people tend to follow healthy food habits during the lockdown. Such healthy practices if followed overtime will augment the prevention of chronic diseases and COVID-19 related complications ${ }^{18,24}$. The present analysis revealed that WFH group had taken an edge over WAO in delaying the food time and even some had skipped their food predominantly, especially the breakfast.

Comparing the times spent watching TV and using mobile phones, use of smart-phones has increased considerably during the lockdown period, spending about 2-4 hours more than the usual in the present study, as reported ${ }^{20}$. On an average, the major proportion of employees in both the groups did not do any physical 
activity, especially outdoors due to restricted movements, safety precautions and closure of gymnasiums, stadiums, parks and swimming pools. The lockdown had reduced the physical activities due to the restricted movement, whereas a study done among Italian population aged $\geq 12$ years reported a slight increase in physical activity ${ }^{1}$. A study among Kurdish population revealed nearly more than one-third of participants had perception of weight gain due to increased appetite ${ }^{25}$. Lack of physical activity is associated with weight gain ${ }^{26}$, and accordingly increased weight gain and decreased physical activity was reported by a higher proportion of WFH group than the WAO group.

Although the WFH group had the advantages of flexible work hours, savings on transportation and fuel costs, and a safer workplace at home, as compared to WAO. Only $26 \%$ indicated their level of work satisfaction to be 'very satisfied' and the remaining was only moderately satisfied or dissatisfied. This may be partly due to the delayed routine activities in WFH group that may hamper time management, disruption of teamwork due to communication gaps and technological issues and inability to adapt to WFH.

\section{Limitations}

The web survey was designed to be accessed on smart devices, and hence only those with the ability to operate smart devices could only undertake the survey. The survey was prepared only in English language considering that a majority would be familiar with the language. Hence, the questionnaire was limited to those who were familiar with the language. Information on socio-economic characteristics such as availability of separate room for WAO group, numbers of rooms available for WFH group and their salaries were not taken into consideration.

\section{Conclusion}

The paradigm shifts of working from home pattern will be a common phenomenon in the near future with the aid of electronic gadgets especially in the current covid19 pandemic period and beyond. Hence, awareness needs to be created on minimizing the gadget-usage besides, judicious planning of the quality time and practice of timely food intake, especially while working from home, to maintain a healthy lifestyle. Periodic rotation of the staff can be strengthened to encourage a balanced lifestyle among working personnel. Weight maintenance and fitness programmes may be mandated for the homebased workers, especially the younger age group to avoid a rise in the proportion of the obese population.

\section{References}

1. Di Renzo L, Guiltier P, Pivari F, Soldati L, Attinà A, Cinelli G, et al. Eating habits and lifestyle changes during COVID-19 lockdown: An Italian survey. J Transl Med. 2020; 18(1):229. https://doi.org/10.1186/s12967-020-02399-5

2. Business Today. Coronavirus in India: 21-day lockdown begins; key highlights of PM Modi's speech [Internet]. March 25, 2020. [cited 2020 Jul 24] Available from: https://www.businesstoday.in/current/economy-politics/ coronavirus-in-india-21-day-lockdown-begins-key-highlights-of-pm-modi-speech/story/399154.html.

3. Government of India. Preventive measures to contain the spread of COVID-19 [Internet]. 2020 Apr 23 [cited 2020 Dec 27]. Available from: https://dopt.gov.in/sites/default/ files/COVIDAttendance.pdf.

4. Government of India. Preventive measures to be taken to contain the spread of Novel Coronavirus (COVID-1 9) [Internet]. 2020 Mar 17 [cited 2020 Dec]. https://www. mohfw.gov.in/pdf/PreventivemeasuresDOPT.pdf.

5. World Health Organization (WHO). Mental health and psychosocial considerations during the COVID-19 outbreak [Internet]. 2020 Mar 17 [cited 2020 Dec 20]. https:// www.who.int/docs/default-source/coronaviruse/mental-health-considerations.pdf?sfvrsn=6d3578af_2.

6. Patridge, Emily F, Tania P. Bardyn. Research Electronic Data Capture (REDCap). J of the Med Lib Association 2018; 106(1):142-44.

7. Cohen J. Statistical Power Analysis Jbr the Behavioral. Sciences. Hillsdale (NJ): Lawrence Erlbaum Associates; 1988. p. 18-74.

8. Partinen M, Bjorvatn B, Holzinger B, Chung F, Penzel T, Espie CA, Morin CM, ICOSS-collaboration group. Sleep and circadian problems during the coronavirus disease 2019 (COVID-19) pandemic: The International COVID-19 Sleep Study (ICOSS). Journal of Sleep Research. 2020 Nov 12.

9. Kumar M, Dwivedi S. Impact of coronavirus imposed lockdown on Indian population and their habits. International Journal of Science and Healthcare Research. 2020; 5(2):88-97.

10. Yang GY, Lin XL, Fang AP, Zhu HL. Eating habits and lifestyles during the initial stage of the COVID-19 lockdown in China: A Cross-Sectional Study. Nutrients. 2021 Mar; 13(3):970. 
11. Marelli S, Castelnuovo A, Somma A, Castronovo V, Mombelli S, Bottoni D, et al. Impact of COVID-19 lockdown on sleep quality in university students and administration staff. J Neurol. 2020; 1-8.

12. Morin CM, Carrier J, Bastien C, Godbout R. Canadian sleep and circadian network. Sleep and circadian rhythm in response to the COVID-19 pandemic. Can J Public Health. 2020; 1-4. https://doi.org/10.17269/s41997-020-00382-7

13. Nuru H, Mamang F. Impact of breakfast skipping toward children health: a review. Int J Community Med Public Health. 2015; 2(3):201-9.

14. Nas A, Mirza N, Hägele F, Kahlhöfer J, Keller J, Rising R, et al. Impact of breakfast skipping compared with dinner skipping on regulation of energy balance and metabolic risk. Am J Clin Nutr. 2017 Jun 1; 105(6):1351-61.

15. World Health Organization (WHO). Coronavirus disease 2019 (COVID-19). Situation Report -32. 2020 Feb 21. https://www.who.int/docs/default-source/coronaviruse/situation-reports/20200221-sitrep-32-covid-19.pdf. Accessed 20 December 2020

16. Butu A, Brumă IS, Tanasă L, Rodino S, Dinu Vasiliu C, Doboș S, et al. The impact of COVID-19 crisis upon the consumer buying behavior of fresh vegetables directly from local producers. Case study: The quarantined area of suceava county, Romania. Int J Env Res Pub He. 2020 Jan; 17(15).

17. Sidor A, Rzymski P. Dietary Choices and habits during COVID-19 lockdown: Experience from Poland. Nutrients. 2020; 12(6).

18. Scarmozzino F, Visioli F. Covid-19 and the subsequent lockdown modified dietary habits of almost half the population in an Italian sample. Foods. 2020 May; 9(5):675.

19. Pellegrini M, Ponzo V, Rosato R, Scumaci E, Goitre I, Benso $A$, et al. Changes in weight and nutritional habits in adults with obesity during the "Lockdown" period caused by the
COVID-19 virus emergency. Nutrients. 2020: 12(7):2016. https://doi.org/10.3390/nu12072016

20. Pietrobelli A, Pecoraro L, Ferruzzi A, Heo M, Faith M, Zoller T, et al. Effects of COVID-19 lockdown on lifestyle behaviors in children with obesity living in Verona, Italy: A longitudinal study. Obesity. 2020; pp. 1382-85. https://doi. org/10.1002/oby.22861

21. Jimenez A, de Hollanda A, Palou E, Ortega E, Andreu A, Molero J, et al. Psychosocial, lifestyle, and body weight impact of COVID-19-related lockdown in a sample of participants with current or past history of obesity in Spain. Obesity Surgery. 2021 Jan 23.

22. Ammar A, Brach M, Trabelsi K, Chtourou H, Boukhris O, et al. Effects of COVID-19 home confinement on eating behaviour and physical activity: Results of the ECLB-COVID19 International Online Survey. Nutrients. 2020; 12(6). https://doi.org/10.3390/nu12061583

23. Ruiz-Roso MB, de CarvalhoPadilha P, Mantilla-Escalante DC, Ulloa N, Brun P, Acevedo-Correa D, et al. Covid-19 confinement and changes of adolescent's dietary trends in Italy, Spain, Chile, Colombia and Brazil. Nutrients. 2020; 12(6).

24. Rodríguez-Pérez C, Molina-Montes E, Verardo V, Artacho R, García-Villanova B, Guerra-Hernández EJ, et al. Changes in dietary behaviours during the COVID-19 outbreak confinement in the Spanish COVIDiet study. Nutrients. 2020; 12(6). https://doi.org/10.3390/nu12061730

25. Galali Y. The impact of COVID-19 confinement on the eating habits and lifestyle changes: A cross sectional study. Food Science and Nutrition. 2021 Food Science and Nutrition. 2021; 9: 2105 - 2113

26. He M, Xian Y, Lv X, He J, Ren Y. Changes in body weight, physical activity and lifestyle during the semi-lockdown period after the outbreak of COVID-19 in China: An online survey. Disaster Med Public Health Prep. 2020; 1-10. https://doi.org/10.1017/dmp.2020.237. 